\title{
HOLISTIC EDUCATION: THE SOCIAL REALITY OF ENGINEERING
}

\author{
HELENA TRBUŠIĆ \\ helena.trbusic@fsb.hr \\ University of Zagreb, Croatia
}

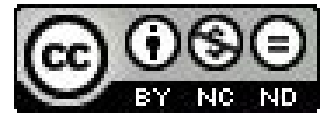

\begin{abstract}
Over the last few decades, scientists exploring the aspects of engineering education and investigating the strong connection between the engineering profession and society have argued for a more rounded, holistic approach to the engineering curriculum. In addition to fundamental technical subjects, they have proposed the inclusion of a broad range of social subjects in order to equip young engineers with social and communication skills relevant for teamwork, and to enhance their awareness about both the way social changes influence the implementation of certain engineering solutions and about the way developments in engineering have a considerable impact on society in general. This paper presents the results of a two-year qualitative study of the importance of social subjects within the engineering academic curriculum at the Faculty of Mechanical Engineering and Naval Architecture in Zagreb, Croatia.
\end{abstract}

Key words: engineering education, non-technical subjects, qualitative study.

\section{INTRODUCTION}

Engineering educators have proposed a number of changes in the outlook of the predominant scheme of engineering curricula. Susan Beder (1999) points out that while the world of technology has undergone substantial transformations since the second half of the $20^{\text {th }}$ century, engineering curricula have basically remained intact. In his description of problems connected with the existing patterns of engineering education, David Goldberg states, "As a faculty advisor in Senior Design since 1990, I have learned how to coach students to successfully solve their problems, but I am continually reminded, year after year, about the mismatch between the education a cold war curriculum provides and the demands of a real-world engineering problems" (Goldberg, 2010, p. 146).

A glance at the history of education for engineers reveals that before the Second World War, students were primarily taught through practical activities, with less emphasis on theoretical knowledge in physics, mathematics and technical fundamentals. However, the Cold War era witnessed a balance between the aforementioned practical skills (personal, interpersonal, and process skills, and product and system building skills) and technical fundamentals, with a steady increase in the emphasis on theoretical technical knowledge (Crawley, Malmqvist, Ostlund, \& Brodeur, 2007). Since the 1970s, some engineering educators have begun to voice concern about the large amount of theoretical input coupled with lack 
of specific skills. During the 1990s, a number of engineers expressed their support for reform of engineering education towards. More specifically, they argued for a more rounded curriculum, which would be directed towards developing practical knowledge, as well as knowledge of non-technical, social subjects. This need for transformation has also been recognized among the engineering academic community, as well as various engineering associations, such as the American Society for Engineering Education, IEAust., American Board of Engineering and Technology, SEFI and IGIP. Still, the way in which this transformation should proceed is still a matter of contention (Beder, 1999; Goldberg, 2010; Jørgensen, 2007). Ulrik Jørgensen, for example, proposes the following solution to the academic stagnation: "The response lies in a new understanding of the role of science in innovation and the use of technology in context. This approach underlines the existing need to bridge the divide between the disciplinary knowledge of the technical sciences and social sciences, and the practical domains of engineering, with their unique knowledge and routines that integrate the social, practical, and technical aspects of technology at work" (Jørgensen, 2007, p. 234).

In the first instance, this paper aims to make a case for a strong non-technical component in engineering education, which would be comprised of, for example, communication skills, practicing teamwork, and training in social responsibility, ethics and critical thinking. The second part of the paper describes the results of the research conducted at the Faculty of Mechanical Engineering and Naval Architecture in Zagreb during the course which took approximately two years (between 2010 and 2012) to complete. The description of the research project is structured with respect to two major topics. The first topic describes what students perceive as being the function of social subjects within their educational training. The second topic concentrates on certain organizational and conceptual difficulties in achieving the desired result of holistic engineering education.

\section{"WHY DO I NEED THIS?": A CASE FOR HOLISTIC EDUCATION OF ENGINEERS}

As a sociologist and an educator of young future engineers, I, just like my colleagues from other departments, have often been confronted with the question posed above. Subtle changes in the identity of the engineering profession have been occurring over the course of the last twenty years. The realization that engineers should be educated in a way that enables them to tackle work tasks of interdisciplinary nature, that is, requiring a broader spectrum of themes than merely scientific and technical fundamentals, has not significantly changed the staunch belief that mechanical engineers deal primarily with problems of purely technical nature. One of the reasons why engineers fail to promote their own ideas and goals to society is because they do not possess sufficient knowledge of the social aspect of their engineering activities (knowledge of social trends, social needs, and changes in politics and the economy) (Beder, 1999). This general knowledge is what Charles Wright Mills (2000) would call "social imagination". It is the goal of holistic engineering education: to understand the social context surrounding 
technical changes and technical innovation. Besides such a general understanding of society and the social system, engineering students also need certain practical skills which can be taught in lectures that concentrate on non-technical subjects and are incorporated into engineering education programs.

\section{TEAMWORK AND COMMUNICATION}

Some solutions to complex problems of engineering assume the ability to work in an interdisciplinary environment. Engineers need an extensive knowledge of other fields of research that go beyond engineering. This is a requirement for engineers working in project teams whose members are professionals from different areas of expertise. The effectiveness of such teams depends, to a great extent, on efficient communication among their members.

Engineering students need some level of knowledge in non-technical and social subjects to be able to communicate with other members of the team on equal ground. Engineers also need to transmit and share their own knowledge, and learn to accept a multiplicity of perspectives. In order to meaningfully participate in teamwork, students should also acquire skills that can facilitate their communication: "Good engineers work in teams and communicate effectively, while always exercising personal creativity and responsibility" (Crawley, Malmqvist, Ostlund, \& Brodeur, 2007, p. 8). They should know how to accept ambiguity (deal with different perspectives), to differentiate (distinguish between perspectives), to synthesize and integrate (find acceptable solutions to all involved, to compromise), and to compare (explore the similarities and differences between perspectives) (Godemann, \& Michelsen, 2011). Communication skills have been identified as a lacking component in young engineers after their graduation (Beder, 1999; Crawley, Malmqvist, Ostlund, \& Brodeur, 2007; Goldberg, 2010). David E. Goldberg (2010) describes how during the course of his career he realized that while young engineers were well educated in technical fundamentals, they were less apt in coping with several basic proficiencies that were of use in teamwork. Among the most conspicuous problems, as he notices, were asking pertinent questions, gathering relevant data, and communicating suggested solutions (Goldberg, 2010). These problems basically pertain to deficiencies in communication skills, which should be taught in a variety of subjects, especially non-technical ones, through presentation exercises, discussion and writing exercises.

\section{SOCIAL RESPONSIBILITY AND SUSTAINABLE DEVELOPMENT}

Communication proficiencies are crucial for successful conflict resolution at the workplace. Not only do engineers need to know how to behave in contentious situations at work, but they should also be able to transfer the skills of conflict resolution and their knowledge of labor rights to their associates. Engineers usually find themselves in management positions, playing the role of leaders in companies at some point of their careers. Today's companies dedicate much focus and attention to public relations policies. Therefore, the strategy and politics of corpo- 
rate social responsibility is an important feature of management. Corporate social responsibility entails, among other things, control and reporting on adequate working hours, freedom of association, health care, discrimination, child labor, forced labor (Bežovan, 2002). Students can learn about the practice of corporate social responsibility by studying examples of companies and their social responsibility policies. Lectures on (corporate) social responsibility should consist of analysis and discussions on how the policies mentioned above can help solve various problems when it comes to the relationship between business activities and society.

Corporate social responsibility is one aspect of the politics of sustainable development. Sustainable development assumes a general outlook on industrial development, which emphasizes the protection of natural resources for future generations, environment conservation, as well as taking care of local communities and treating workers fairly. The precepts of sustainable development have been implemented in many high school and university educational programs. Educational processes are seen as one of the instruments of promoting sustainability discourse (Godemann, \& Michelsen, 2010). Students of engineering play an especially important role in this respect because they devise and implement new technical solutions. These new solutions should adhere to certain ecologically viable standards. As Nicholas A. Ashford (2004, p. 239) observes, "The focus is on engineering, more than on natural and physical sciences or on social science, because the activities that drive the industrial state - the activities that implement scientific advance - are generally rooted in engineering". Students of engineering need to be made aware of the important and far-reaching effect they have upon their community and society in general. Before proposing international solutions for local communities, they should know something about their traditions and history so they do not do harm to the existing social equilibrium, such as job losses or threats to traditions and an accepted way of life (Pavlova, 2009). When designing and launching new products, they are supposed to take into consideration how those new products may affect people in their surroundings: "To do this, students must be technically expert, socially responsible, and inclined to innovate. Such an education is essential for achieving productivity, entrepreneurship, and excellence in an environment that is increasingly based on technologically complex systems that must be sustainable" (Crawley, Malmqvist, Ostlund, \& Brodeur, 2007, p. 10).

\section{ENGINEERING ETHICS AND CRITICAL THINKING}

Another important task of engineering education is to point out the possible consequences of decisions made in the field of engineering. The history of environmental catastrophes and technical accidents has demonstrated that the engineering profession needs a strong professional code because even small decisions can bring about unwanted effects. One of the tasks of engineering education is to train students, future engineers, how to react in certain ethically delicate situations. Mere rules are not enough to provide students with a framework for actively pursuing ethical standards. Analyzing realistic fictional cases and ethical dilemmas can prepare students for real-life issues and problems at the workplace. 
As Charles Harris Jr., Michael S. Pritchard, \& Michael J. Rabbins (2009, p. 19) point out, "Engineers, like other professionals, are case-oriented. They do not work in generalities, and they must make decisions. The study of cases helps students understand that professional ethics is not simply an irrelevant addition to professional education but, rather, is intimately related to the practice of engineering".

Anticipation of potentially contentious situations requires the ability to think critically. Critical thinking is a desired goal at all levels of general education. It assumes the questioning and constant re-evaluation of accepted truths. The incorporation of critical thinking into the engineering curriculum can have substantial benefits for the engineering profession. Margarita Pavlova (2009) has suggested a model for the inclusion of critical thinking into the curriculum through what she calls the "re-think" principle. Students are required to study a problem and, through guided classroom discussions, propose innovative solutions which go beyond the prevalent, routine answers their profession already offers. One example is the "Buddhist economy," "which is based on the idea of "enoughness" of appreciating both human needs, limitations and appropriate use of technology" and of emphasizing "that the aim ought to be to obtain the maximum amount of well-being with the minimum amount of consumption" (Pavlova, 2009, p. 80).

Engineering educators have produced a large body of texts describing the most important skills that engineers need to possess in order to perform their jobs to a certain standard. While some changes fail to produce desired results, ever new designs of engineering curricula are being proposed to accommodate the needs of the business world and the industry. Still, David E. Goldberg, Andreas Cangellaris, Michael Loui, Raymond Price, \& Bruce Litchfield (2008) point out that the changes are too slow and cannot provide a timely answer to industrial needs. One of the reasons is because the proponents of change sometimes neglect one of the chief actors of engineering education: the students. The following study thus focuses primarily on students and their views on the changes entailing the inclusion of social subjects into the curriculum. There have already been studies into the students' perspective on the content of their education (Crawley, Malmqvist, Ostlund, \& Brodeur, 2007) but they have been narrowed down to studying the need for practical knowledge acquisition. The success of the engineering education reform depends on the acceptance of these changes by the students. Therefore, a deeper scientific understanding and further research into the attitudes of students is required.

\section{DATA AND METHOD}

The research data have been gathered from students at the Faculty of Mechanical Engineering and Naval Architecture at the University of Zagreb. The subjects of Sociology and Industrial Sociology have been present in the Faculty's curriculum for several decades. General Sociology is taught in the first semester, while Industrial Sociology - towards the end of education at the Faculty. In the past ten years, the Faculty has introduced more non-technical subjects dealing with law, 
economics, management, and psychology. These subjects are mostly elective, with some of them being obligatory, depending on the student's major. The new orientation towards broadening non-technical knowledge came as the result of adherence to the propositions of ASIIN (Akkredititierungsagentur für Studiengänge der Ingenieurwissenschaften, der Informatik, der Naturwissenschaften und der Mathematik), a German quality assurance agency. The goal of the agency is rectify the engineering curriculum by making it more interdisciplinary and by including in it more non-technical content (10 percent of the whole workload).

What has given impetus to further research were several years spent on observing students' behavior and attitudes towards non-technical subjects in general and sociology in particular. Discussions about related issues were gradually incorporated into several lectures over the course of four years. Students were also required to write an essay on the importance of social subjects for their overall education. Their output was then used to construct semi-structured interviews on the same topic. So far we have conducted nineteen interviews. The duration of interviews was mostly between thirty-five and fifty-five minutes. The interviews were transcribed and analyzed in accordance with the general recommendations of qualitative analysis (Denscombe, 2007; Glaser, \& Strauss, 1999; Silverman, 1993). The first seven interviews were transcribed in full and later interviews were transcribed with respect to the emergent themes from previous interview transcriptions. We have also written notes or memos during our research, which contained important ideas and new focus points that were noticed or came to mind. The memos often served to facilitate the analysis of transcripts. We employed the method of inductive thematic analysis and paid special attention to perceived anomalies in expected answers (Braun, \& Clarke, 2006). While collecting data, we continually added new questions and abandoned those that were non-conclusive. The transcripts were coded and analyzed according to several relevant thematic units. Importantly, not all of the thematic units have been covered in this paper on the ground that the material would be too overwhelming and beyond the scope of this paper.

\section{RESEARCH RESULTS}

\section{Students' perspectives on the importance of non-technical subjects}

The aim of this research is to understand how students perceive the presence of social subjects in their studies program at the Faculty. The expectations of potential benefits gained from such a component in their education turned out to be connected with their perception of engineering in general, or, more specifically, what they believed to be the essence of the work of an engineer. The following statement once again reiterates the traditional view of engineering as a discipline primarily demanding good knowledge of physics and mathematics on the part of the student: "I was never interested in subjects such as law or the Faculty of Humanities and Social Sciences because I was always good at mathematics, physics and I definitely saw myself doing this..." (I7); "I wanted something that was connected with mathematics, physics because it's interesting and important. I thought mechanical engineering was the best, the most applicable" (I10). 
The students' first encounter with sociology in the first year of study usually results in surprise. Some students noted that they or their colleagues could not understand the necessity of such subjects and even had a hard time accepting it as part of their curriculum. "Statistically it is normal that people, when they see it for the first time, will say: 'Sociology?! What the hell?! Why is this in the first year? Why do I need this?' you see. And then any kind of discussion regarding that, even when you try to accommodate them and say 'Alright, look, well, engineers they have always changed the world and society, if you will. So it is a great influence on society, so it would be good if you heard something about that.' 'Ah, whatever.' I mean, ... this is the general attitude, you know" (laughter) (I2); "I think it was, "Well, I chose Naval Architecture, why do I need this?" /sociology/" (I12); "When I came to the Faculty I was surprised that we had sociology. That was really strange" (I18).

Students who had a positive attitude towards social subjects pointed out that their appreciation of non-technical subjects came gradually, during the course of their education: "In my first year of study, I thought it/having sociology/was strange. Now it's less strange to me. You do need something that is non-technical" (I18); "And then I realized that making money wasn't the most important thing, that knowing how to act around people is also important so I saw that there was something to that. And in general, in life and society you realize that money isn't the most important thing, but relationships with people, so while becoming more mature my attitude towards the subject / social subject(s)/ changed" (I15).

When students start to think about their future, their job and employment, they start to feel somewhat anxious and unprepared. They find it disturbing that the knowledge they have received needs to be adequately placed in the context of the working environment, with all its essentially social aspects. Moreover, they come to realize that they not only lack the knowledge and the ability to understand their position in society, but they are also devoid of the appropriate sociological imagination. It is at that time that they begin to show a newly found appreciation of social sciences. When they find themselves filled with fear of not being able to cope with the new workplace environment, they become aware that some answers cannot be found mathematics and theoretical technical knowledge. When asked what they perceived to be missing from their education, they provided the following answers: "Well, for me, I would like to hear about, well in general about the functioning of, of the workplace, what it all looks like, for me for example, when I graduated/for bachelor/, I wasn't sure whether I should continue or not; I thought I wouldn't, and then I, I felt this enormous fear because I felt I was completely unprepared for work, or anything... The first three years are, ok, are really about engineering and the expertise and ok, we need to know about that, I'm not saying we don't, but some are too much about that, and nothing on other things, like communication" (I3); "About real topics, so topics in business, because engineering is one thing and business is another. How to run a company, how to make profit, how to employ people and how to behave towards them, so maybe a little psychology, leadership" (I7); "Well, they're probably important for those "soft skills", and... So, to see a slightly broader image of it all, not just cog wheels and that's it. (...) Well, it sounds like something people just say over and over again, but, yes, we engineers don't do just engineering work but we have 
to do, you have some kind of management and all those things we don't want to do, so we have to, we have to know about it" (I6).

The above examples show that students are led to believe that social subjects can help them achieve proficiency in communication skills. Some students have also expressed the need to acquire knowledge of group work and teamwork, writing skills, presentation skills: "Everyone expects us to work in teams. But nobody has taught us the basics of teamwork. I don't mean the basics like 'Teamwork is this and that', but exercising teamwork" (I10); "There should be sociology, psychology, politics and economy. I would introduce Croatian language at this Faculty. I have the feeling that half of the students are illiterate. You can't be an illiterate engineer" (I18); "It is a shock for us when we have to give a presentation, it's... you freeze in front of people, it's a bit, I mean, stage fright and all that. I think that that sort of thing requires attention... that a person feels relaxed, that he is capable of communication and... adequately and without fear present his ideas" (I4).

This is the knowledge and skills which students believe they should acquire during their education. It would help them practice engineering in a satisfactory way in their future professional careers. However, many of the answers indicate somewhat ambiguous opinions about the usefulness of studying social subjects. More often than not, students are not really clear about the reasons for introducing non-technical subjects into their technical education. When asked about the benefits of studying non-technical subjects, they provided the following answers: "Well, for me personally, I don't know what those "direct benefits" is supposed to mean. For me, I don't know, to me it is useful because I find it interesting. That's it. That would be the benefit of these subjects" (I3); "To get a break from technical subjects" (I18); "Yes. Three years, that is, the first two years are extremely demanding and difficult. There are lots of technical subjects and this is refreshing. Like something new, which is great" (I7).

The above quoted statements may reflect the students' ingrained opinion that the usefulness of a subject is measured by the immediate and direct applicability of knowledge or skill being taught. It might be hard for students to distinguish the direct benefits non-technical subjects have to offer for their profession. Edward Crawley, Johan Malmqvist, Soren Ostlund, \& Doris Brodeur (2007), for instance, argue that the existing model of adding social subjects to the total body of theoretical knowledge is not adequate: "Simply broadening the science base in a more interdisciplinary direction, including the social sciences and humanities, may not have been a satisfactory solution. The mere addition of topics to the curriculum does not change engineering practices or provide a better integration of knowledge" (Crawley, Malmqvist, Ostlund, \& Brodeur, 2007, p. 234).

\section{PERCEIVED OBSTACLES TO HOLISTIC ENGINEERING EDUCATION}

Although many engineering educators believe it is high time to reform engineering education, there are, just like in the case of every institutional reform, certain obstacles of organizational and conceptual character (Goldberg, Cangellaris, Loui, Price, \& Litchfield, 2008). As I have mentioned elsewhere, social subjects have been added to the curriculum, but their contribution to holistic education has been only partly successful, since it occurs to contribute merely to the overall 
theoretical body of knowledge (Crawley, Malmqvist, Ostlund, \& Brodeur, 2007). Many students feel that social subjects are an additional and unnecessary burden. They say that the enormous amount of work connected with the technical fundamentals leaves little space for the appropriate acquisition of non-technical subjects: "I don't know, maybe they're preoccupied with these technical/subjects/, like thermodynamics, that's like, infamous, and they don't feel like doing it, like, 'Ah, who would do that...' probably. But, really, we're preoccupied with all sorts of things and then, when something like that comes along, you don't feel like doing it anymore" (I6); "Well, I think that /lower level of difficulty of non-technical subjects/ is important to everybody, even other people, because people also think they would rather have some time off than to invest themselves into some kind of elective/coursel, that's like, I don't know, like religious teaching in high school, so you probably expect an excellent grade from it" (laughter) (I3).

A problem has been identified by educators, who are the leading proponents of changes in the curriculum that emphasize the importance of so-called soft-skills.

These are essentially the "what" and "how" questions that engineering educators commonly face. Focusing on the first question, there is a seemingly irreconcilable tension between two positions in engineering education. On one hand, there is the need to convey the ever-increasing body of technical knowledge that graduating students must master. On the other hand, there is growing acknowledgment that engineers must possess a wide array of personal and interpersonal skills; as well as the product, process, and system building knowledge and skills required to function on real engineering teams to produce real products and systems" (Crawley, Malmqvist, Ostlund, \& Brodeur, 2007, p. 10).

The new demands pose a significant organizational challenge because the new additions are extremely difficult to incorporate into the existing "traditional program structure" (Fromm, 2003). Furthermore, the teaching staff is inclined to show a certain degree of resistance to the practical, as well as conceptual, changes in the curriculum. David Goldberg, Andreas Cangellaris, Michael Loui, Raymond Price, \& Bruce Litchfield (2008) noted that while many engineering educators in general support the reform, they object to the possibility that they themselves should adjust to and accommodate the curriculum changes, a kind of "educational NIMBY". Although the present study did not include the teaching staff, we asked the students to share their impressions about the way their professors view the changes and the incorporation of "soft subjects" into the engineering curriculum. When asked if professors justify the need for those subjects(since students themselves have mentioned that they were surprised with the inclusion of sociology), the interview students came up with negative answers: "Hm, no one told us anything. Absolutely nothing" (I3); "Nothing special. Nothing special" (I7); "Nobody told us anything about that" (I11).

These answers do not tell us much about the possible opinions of the engineering professors. They might, at best, be indicative of a kind of ambivalence and the mentioned "educational NIMBY." However, one student reported an extremely negative statement given by a professor at a lecture, which perfectly indicates the prototypical insistence on sticking to fundamentals while at the same time depreciating the non-technical part of engineering education: "Well I think that / 
students/from those so-called strictly engineering departments; construction, energetics, that they have a negative perception, or rather, a belittling attitude towards non-technical subjects, including management. I remember like it was yesterday when a professor teaching mechanics once said on a lecture, he said: "You have to know engineering, you have to know technical things and those over there, managers of some sort, they think they can teach anything" (I7).

While there was only one respondent decidedly stating that some teachers frown upon the teaching of so-called soft subjects, there were also many reports of equally negative attitude on the part of the students. When asked what students tend to think of the presence of social subjects in the curriculum, the respondents said: "Standard stuff. 'Why do we need this?'" (I18); "A lot of people avoid non-technical /subjects/. (...) It's like 'I came to a technical faculty, I don't need non-technical things'" (I16); That's why it is called mechanical engineering and naval architecture, so mechanical engineering, so technical. I thought/sociology/was a necessary evil. It didn't interest me before, it doesn't interest me now, it will never interest me (I14); The attitude is like "Tha$t^{\prime}$ s gibberish. I don't need that" (I15).

Students openly express their dissatisfaction with the requirements posed by the curriculum, and especially the presence of non-technical subjects. Their main objections pertain to the amount of workload. As they say, it does not allow time and energy for a detailed study of social subjects. Their responses also point to their confusion regarding the benefits and usefulness of social subjects. The responsibility for their confusion partly lies with the teaching staff, which does not explain the facets and benefits of holistic engineering education, albeit the teachers formally accept its goals.

If students' dissatisfaction and misunderstanding of the social component in the curriculum is in a way the reflection of attitudes adopted by the engineering professors at faculties over the world, then this rejection poses the question of a certain kind of perception of the work done by engineers and a certain kind of perception of the identity of engineers. Sharon Beder (1999) pointed out that, historically, the concept of "engineering as applied science" was accepted by the engineering community in order to gain status and to distinguish their community from "technicians, mechanics and skilled craftsmen in the occupational hierarchy". As D. Goldberg (2010, p. 153) indicates, "For example, engineering academics defend »the basics « against the encroachment of »soft « subjects, and it is even fairly common for engineering faculty to ridicule »soft « subjects and those who teach them; it is the rare engineering department, indeed, that can bring itself to approve course offerings in »soft « subjects and even rarer for engineering colleges to find it acceptable to offer tenure to those with "soft « disciplinary backgrounds". The curricular change apparently calls for a transformation of the existing paradigm among engineering professionals.

Thomas S. Kuhn (1999) has described the dynamics of change in the history of science, claiming that science progresses in a series of "jumps" or "scientific revolutions." A scientific revolution, with its unique explanations of the world around us, represents a radically different scientific approach. In the beginning, this change is resisted by the majority of scientists. The change in perception of what the 
engineering curricula should offer in order to complement the engineering work environment of today could be seen as an example of shifting paradigms. Just like T. S. Kuhn describes it, at the early stages of the proposed revolutionary changes, there is a substantial division in the scientific community. Apart from educators, who are strong proponents of engineering education, the rest of the engineering scientific community is positioned on a continuum between those who are positively inclined those who are ambivalent and those engineering educators who are overtly hostile towards the changes. D. Goldberg, A. Cangellaris, M. Loui, R. Price, \& B. Litchfield (2008) point out the unwillingness to shift to this new paradigm of engineering education and identifies the slow and cumbersome democratic processes of decision-making at faculties as an important factor hindering change. Therefore, if the curriculum is to truly grant a more holistic education to the engineering professionals, the reformers need to take into consideration the resistance at the organizational level, and try to come up with the ways to speed up the change and motivate the teaching staff to actively participate in the implementation of those changes.

\section{CONCLUDING REMARKS}

Engineering educators and various institutions responsible for the integrity of the engineering profession have welcome the changes in engineering curricula with enthusiasm. These changes imply a shift towards a new paradigm of engineering and engineering education. This new paradigm is a move away from the insistence on the scientific basis of technical education, which is comprised of theoretical knowledge in mathematics, physics and other purely technical subjects. The new paradigm, on the other hand, is designed to include a broader set of non-technical, social subjects and the acquisition of practical skills.

The research conducted at the Faculty of Mechanical Engineering and Naval Architecture was designed to understand how students at the chosen university perceive of the significance of the non-technical part of their education. The results showed that a large number of students believe that some skills, such as communication and presentation skills, leadership, and teamwork, are essential for their work prospects and, therefore, should be included in the program. They also emphasized that this kind of knowledge should be acquired through practical means, and less through studying social theory. This points to the fact that they are more oriented towards learning simple skills than understanding how social systems function and how engineers can or should function within the social system. One of the obstacles that impede implementing holistic engineering education is this very lack of understanding of the "big picture" at the organizational level. The traditional view connected to the mentioned "old paradigm" of engineering still continues to exist on universities while "soft" subjects are being marginalized or not taken too seriously. In order to succeed in reform towards holistic engineering education, professors and students at engineering educational institutions need to acknowledge the importance of the social component of engineering education and the social context of engineering activity. 


\section{REFERENCES}

Ashford, N. A. (2004). Major challenges to engineering education for sustainable development: what has to change to make it creative, effective, and acceptable to the established disciplines? International Journal of Sustainability in Higher Education, Vol. 5, 3, 239-248.

Bell, D. (1999). The Coming of Post-Industrial Society - a Venture in Social Forecasting. New York: Basic Books.

Beder, S. (1999). Beyond technicalities: expanding engineering thinking. Retrieved on January 17, 2013, from www.ouw.edu.au/ sharonb/enged99.html.

Bežovan, G. (2002). Socijalna odgovornost gospodarstva i iskustva u Hrvatskoj [Social Responsibility of the Economy and Experiences in Croatia]. Revija za sociologiju, Vol. 33, 1-2, 17-32.

Braun, V. and Clarke, V. (2006). Using thematic analysis in psychology. Qualitative Research in Psycho$\log y, 3$ (2). 77-101.

Crawley, E., Malmqvist, J., Ostlund, S., Brodeur, D. (Eds.). (2007). Rethinking Engineering Education - the CDIO-Approach. New York: Springer.

Denscombe, M. (2007). The Good Research Guide for Small-scale Research Projects. New York: Open University Press.

Fromm, E. (2003). The Changing Engineering Educational Paradigm, Journal of Engineering Education, 92(2), 113-121.

Glaser, B., \& Strauss, A. (1999). The discovery of grounded theory: strategies for qualitative research. New York: Aldine de Gruyter.

Godemann J., \& Michelsen G. (Eds.). (2011). Sustainability Communication - Interdisciplinary Perspectives and Theoretical Foundations. Dordrecht, Heidelberg, London, New York: Springer.

Godemann, J., \& Michelsen G. (2011). Sustainability Communication - An Introduction. In: J. Godemann, \& G. Michelsen (Eds.), Sustainability Communication - Interdisciplinary Perspectives and Theoretical Foundations (pp. 231-262). Dordrecht, Heidelberg, London, New York: Springer.

Godemann, J. (2011). Sustainability Communication as an Inter and Transdisciplinary Discipline. In: J. Godemann, \& G. Michelsen (Eds.), Sustainability Communication - Interdisciplinary Perspectives and Theoretical Foundations (pp. 39-51). Dordrecht, Heidelberg, London, New York: Springer.

Goldberg, D. E. (2010). The Missing Basics and Other Philosophical Reflections for the Transformation of Engineering Education. In: D. Grasso, \& M. Brown Burkins (Eds.). Holistic Engineering Education - Beyond Technology (pp. 145-158). New York, Dordrecht, Heidelberg, London: Springer.

Goldberg, D., Cangellaris, A., Loui, M., Price, R., Litchfield, B. (2008). Ifoundry: Engineering Curriculum Reform without Tears Retrieved from http://search.asee.org/search/fetch;jsessionid=3reaw2vtpt fb6?url=file $\% 3 \mathrm{~A} \% 2 \mathrm{~F} \% 2$ Flocalhost $\% 2 \mathrm{FE} \% 3 \mathrm{~A} \% 2 \mathrm{Fsearch} \% 2 \mathrm{Fconference} \% 2 \mathrm{~F} 17 \% 2 \mathrm{FAC} \% 25202008 \mathrm{~F}$ ull1667.pdf\&index $=$ conference_papers\&space $=129746797203605791716676178 \&$ type $=$ application $\% 2$ Fpdf\&charset $=$.

Grasso, D., \& Brown Burkins, M. (Eds.). (2010). Holistic Engineering Education - Beyond Technology. New York, Dordrecht, Heidelberg, London: Springer.

Harris Jr., C., Pritchard, M. S., \& Rabbins, M. J. (2009). Engineering Ethics - Cases and Concepts. Wadsworth: Cengage Learning.

Jørgensen, U. (2007). Historical accounts of engineering education. In: E. Crawley, J. Malmqvist, S. Ostlund, \& D. Brodeur (Eds.). Rethinking Engineering Education - the CDIO Approach (pp. 216-240). New York: Springer.

Kuhn, T. S. (1999). Struktura znanstvenih revolucija [The Structure of Scientific Revolutions] Zagreb: Jesenski i Turk.

Mills, C. Wright (2000). The Sociological Imagination. New York: Oxford University Press.

Pavlova, M. (2009). Technology and Vocational Education for Sustainable Development. Dordrecht, The Netherlands: Springer.

Pawley, A., L. (2009). Universalized Narratives: Patterns in How Faculty Members Define "Engineering". Journal of Engineering Education, October, 309-319.

Sennett, R. (2006). The Culture of the New Capitalism. New Haven, London: Yale University Press.

Silverman, D. (1993). Interpreting Qualitative Data: Methods for Analysing Talk, Text and Interaction, London: Sage Publications. 